\title{
El comercio directo de maderas para la construcción naval española y de otros bienes provenientes de la región del Báltico sur, 1700-1783*
}

\author{
Rafal Reichert \\ CESMECA-UNICACH
}

RESUMEN: El presente trabajo es una primera aproximación al tema del comercio directo entre la región sur del Báltico y España, tema muy poco examinado por la historiografia española. A través de los registros digitales del estrecho de Sund, el punto donde los barcos pagaban un derecho de tránsito a la Corona danesa, se realizó un análisis del movimiento marítimo y su volumen entre ambas regiones en el periodo de 1700 a 1783. Los resultados se profundizaron con el empleo de las historiografias polaca, española y europea, lo que permitió establecer nuevas perspectivas de la vida comercial tanto de España, como de los países del Báltico sur. Principalmente, el estudio se centra en la presentación de los aspectos geopolíticos, marítimos y económicos de este comercio directo, y en especial en el análisis de los envios de madera para la construcción naval española. Finalmente, el propósito de este trabajo es demostrar que realmente existió comercio directo entre el Báltico sur y España que, aunque fuera escaso en un marco global, demostró su utilidad frente al monopolio anglo-holandés en el tráfico con las diferentes regiones de dicho mar.

PAlabRas ClaVE: Báltico Sur; España; comercio directo; madera; Gdansk; Cádiz; siglo XVIII.

The Direct Trade of Woods for the Spanish Shipbuilding Industry and other Goods from the Southern Baltic Sea Region, 1700-1783

ABSTRACT: The present work is the first approach to theme of the direct trade between the southern region of the Baltic Sea and Spain, the issue very little known and generalizes by Spanish historiography. Thus, for help of the

* Abreviaturas: Biblioteca Nacional de España (BNE). 
digital records of the Sound Strait, the checkpoint where ships paid a right of transit it to the Danish Crown, was conducted an analysis of the maritime movement and its volume between both regions in the period of 1700-1783. The results of this research were deepened with the employ of the Polish, Spanish and European historiographies that allowed establishing new perspectives of the commerce life of both regions (Spain and countries of the South Baltic). The primary focus of study focused on the presentation of economic, geopolitical and maritime aspects of this direct trade, where mayor attention was offered to the analysis of wood and timber shipments for the Spanish shipbuilding industry. Finally, the purpose of this work was to demonstrate that actually existed the direct trade between the South Baltic and Spain, which perhaps was small in a global context, however showed its utility against Anglo Dutch monopoly in traffic with different regions of this sea.

KEY WORDS: South Baltic; Spain; direct trade; timber wood; Gdansk; Cadis; 18th century.

Varias obras de la historiografía naval española ${ }^{1}$ mencionan con cierta frecuencia que, a causa de la desforestación en la parte norte de la Península Ibérica provocada por la alta demanda de maderas para la industria naviera hispana, inició el comercio de esta materia prima, más otros pertrechos navales, con distintas regiones de Europa, en especial con el mar Báltico. Este último espacio geográfico, que contaba con una gran abundancia de bosques vírgenes, desde los tiempos de la creación de la Liga Hanseática aportaba maderas de roble, pino y abeto, así como otros recursos para la construcción naval, tanto para cubrir las necesidades de la propia región, como de otras naciones europeas. Los países del área que más se beneficiaron de este comercio para desarrollar sus marinas fueron Suecia, Dinamarca, Holanda, Inglaterra y Francia. A pesar del predominio de dichas naciones en el comercio de maderas bálticas, también es posible identificar información sobre cómo Portugal y España buscaban establecer, desde el siglo XVI, un comercio directo con la región del Báltico sur para romper con el monopolio comercial, principalmente de neerlandeses e ingleses ${ }^{2}$.

El objetivo principal del presente artículo es demostrar que, efectivamente, funcionó un comercio directo de maderas y de otros bienes entre los puertos

1 SERRANO MANGAS, 1986. CASADO SOTO, 1988. RAHN PHILLIPS, 1991. ODRIOZOLA OYARBIDE, 1996. PÉREZ MALLAINA BUENO, 1982. BARKHAM, 1984. CRESPO SOLANA, 2000. CEREZO MARTÍNEZ, 1989. DÍAZ ORDÓÑEZ, 2003. GOODMAN, 1997. ZABALA URIARTE, 1983, entre otros.

2 PEARSON, 2009. ISRAEL, 1990. JANZEN, 1998. HEERES, 1988. HORLINGS, 1995. ORMROD, 2003. OAKLEY, 1993. DAVIS, 1962. ATTMAN, 1973. GLETE, 1993. KAHK, 1997. FEDOROWICZ, 1980. BOGUCKA, 1970. NORTH, 1984-1988, entre otros. 
españoles y los bálticos. El estudio de su estructura, frecuencia y volumen nos permitirá entender con mayor detalle el funcionamiento de este ramo comercial en España. Con este propósito, durante los últimos meses se investigaron los registros mercantes y el movimiento marítimo de los barcos que cruzaron el estrecho de Sund $^{3}$ en el periodo comprendido entre 1700 y 1783, lo que permitió recoger datos sobre el comercio directo entre los países del Báltico y España. Es importante subrayar que en esta aportación solamente se realizan los análisis correspondientes a la región sur de dicho mar, y el área geográfica del estudio se extiende desde Lübeck (actual Alemania) hasta Memel (actual Kláipeda, Lituania). ${ }^{4}$ A través de los registros se pudo contabilizar el total de buques que atravesaron la ruta entre el Báltico sur y España, distinguir sus cargamentos y encontrar sus puertos de partida y destinos finales; además, se pudieron identificar los datos generales de los capitanes que dirigían cada barco (nombre, apellido y lugar de procedencia).

La temporalidad en la cual se sitúa el estudio se eligió debido a diversos acontecimientos cruciales en la historia española y en la europea, que influyeron en el destino y la evolución de la industria naval hispana tanto real como mercante. Se abarca entonces un periodo extenso que incluye desde el cambio dinástico en el trono de España de la Casa de los Austrias a la de los Borbones - suceso que permitió la renovación de las fuerzas navales, proyecto introducido por el ilustre ministro José Patiño-, hasta el auge de la marina española durante los tiempos de Carlos III (1759-1788).

Por otro lado, durante ese periodo en la región del Báltico sur se observa una dinámica de importantes cambios geopolíticos a partir de los cuales emergieron nuevas potencias europeas (Prusia y Rusia) y también la desintegración de la Mancomunidad de Polonia y Lituania o República de las Dos

3 El registro del peaje (derecho de tránsito) de Sund contiene información detallada de todos los barcos que entraron o salieron del Báltico por los estrechos daneses. La mención más antigua conservada en el registro data de 1497, y los volúmenes completos incluyen el periodo entre 1557 y 1857 , año en que se abolió el peaje. La serie de Sund contiene valiosa información sobre la navegación y el comercio marítimo del mundo atlántico. Los documentos se custodian en el Archivo Nacional de Dinamarca, en Copenhague. Actualmente es posible revisar los registros en línea, en la dirección web http://www.soundtoll.nl/index.php/en/welkom., donde se pueden consultar los volúmenes correspondientes a los siglos XVII, XVIII y XIX.

4 Los puertos del Báltico sur que participaron en el comercio directo con España y que se analizan en este artículo son: Lübeck, Greifswald, Rostock, Stralsund, Wismar, Wolgast, de la actual Alemania; Swinoujscie (Swinemünde), Szczecin (Stettin), Kolobrzeg (Kolberg), Darlowo (Rügenwalde), Slupsk (Stolp), Gdansk (Danzig), de la actual Polonia; Kaliningrado (Königsberg) y Baltisk (Pillau), ambos de la actual Rusia; y finalmente Kláipeda (Memel), de la actual Lituania. Es importante subrayar que en el presente artículo se emplean los nombres alemanes, estos entre paréntesis, porque así aparecen en los registros del estrecho y fueron comúnmente utilizados durante la época que abarca el estudio. La única excepción es Gdansk. En este caso se utiliza el nombre polaco debido a su origen histórico, siempre conectado con Polonia. 
Naciones. Estos complejos contextos históricos demuestran la intensa coexistencia entre diferentes espacios geográficos europeos, que acentuaron los acontecimientos políticos, bélicos, comerciales y navales como factores que afectaban a las naciones y sociedades a nivel no solamente regional, sino también mundial, ya que no se puede estudiar la historia del mundo atlántico excluyendo el Báltico, región que desde la Edad Media aportaba materias primas forestales y productos agrícolas al occidente europeo.

MAPA 1. Los puertos del Báltico sur que participaron en el comercio directo con España, siglo XVIII

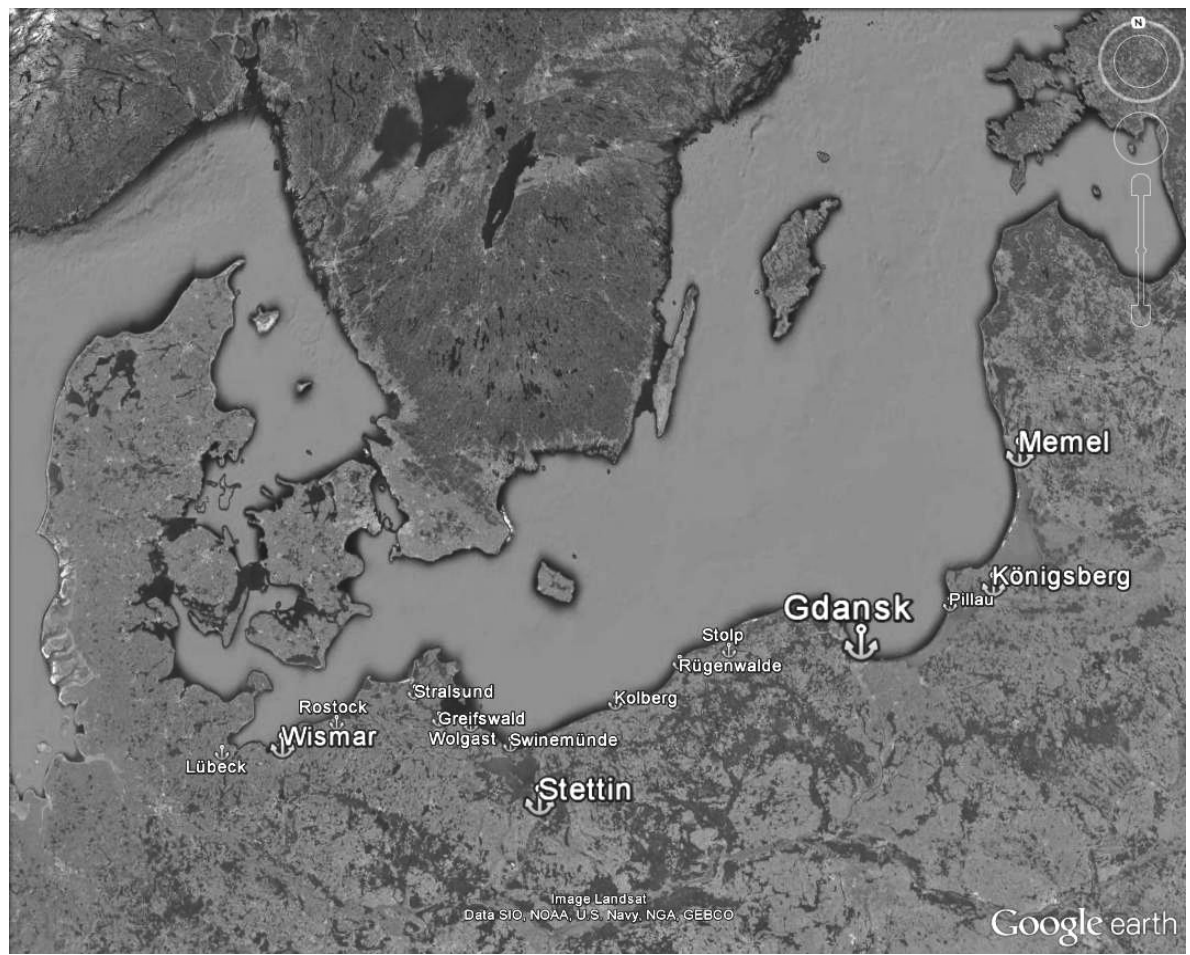

Fuente: propia con base en Google Earth.

\section{SITUACIÓN GEOPOLÍTICA Y COMERCIO DIRECTO ENTRE EL BÁLTICO SUR Y ESPAÑA, 1700-1741}

Pocos meses después de la muerte del rey Carlos II (1665-1700), ocurrida el 1 de noviembre de 1700, estalló el conflicto por la herencia del trono español 
entre los Habsburgo y los Borbones. La llamada Guerra de Sucesión Española (1701-1713) fue un conflicto internacional con actividades bélicas principalmente entre la Corona francesa, la británica y los Austrias. El tema de la herencia también causó fuertes desacuerdos a nivel nacional, ya que Castilla y Navarra se mantuvieron fieles al candidato borbónico (el duque de Anjou, futuro Felipe V de España, 1700-1746), mientras la mayor parte de Aragón se declaró del lado austriaco (a favor del archiduque Carlos). Los combates en España fueron favorables a Felipe V, quien tras la victoria de Almansa (1707) logró el control sobre Aragón y Valencia. En 1711, el candidato de los Habsburgo fue elegido emperador del Sacro Imperio Romano Germánico con el nombre de Carlos VI (1711-1740). Este acontecimiento cambió el punto de vista de las potencias europeas que apoyaban esta candidatura, de manera que Gran Bretaña y Holanda, para impedir que los Austrias concentraran un excesivo poder, suspendieron los combates y comenzaron las negociaciones de paz, las cuales terminaron con la firma del Tratado de Utrecht (1713). Mediante estos acuerdos y el reconocimiento de Felipe $\mathrm{V}$ como rey hispano por las principales fuerzas europeas, España perdió algunas de sus posesiones en Europa (Gibraltar, Menorca y Flandes), pero conservó la unidad de los territorios ultramarinos. Con el nuevo monarca, el Imperio entró en una nueva etapa de restauración tanto política, administrativa y económica, como militar y naval, esta última llevada a cabo por los ministros José Patiño, José del Campillo y Cossío y el marqués de la Ensenada 5 .

Mientras en el occidente de Europa se decidía la sucesión española, estalló la Gran Guerra del Norte (1701-1721), en la que una alianza entre los reinos de Dinamarca y Noruega, Rusia y Prusia se enfrentó contra Suecia. En 1704, en el conflicto fue involucrada Polonia por los ambiciosos planes de su rey Augusto II (1697-1733), quien intentó restablecer la posición privilegiada de la Mancomunidad de Polonia y Lituania en Europa Central y Oriental ${ }^{6}$. Tras varias derrotas de su ejército, compuesto por tropas sajonas, polacas y lituanas, el rey fue obligado a abandonar el país, que durante los siguientes seis años fue ocupado por los ejércitos de Carlos XII de Suecia (1697-1718). En 1706, el monarca sueco invadió Sajonia y, mediante la paz de Altranstädt, obligó a Augusto II a abdicar del trono polaco ${ }^{7}$.

Tras el fracaso de la campaña sueca contra Rusia en el oriente y la desastrosa derrota del ejército de Carlos XII en la batalla de Poltava en julio de 1709, Suecia perdió la posición privilegiada en la Gran Guerra del Norte. Augusto II, consciente de la debilidad militar de las tropas sajonas, polacas y

5 Sobre la Guerra de Sucesión Española y Felipe V véase: CALVO, 1988. VOLTES, 1990. KAMEN, 2000.

6 Augusto II al mismo tiempo reinaba en Sajonia.

7 STASZEWSKI, 1998: 196. 
lituanas, tuvo que aliarse con el zar Pedro I el Grande (1682-1725) para, con el auxilio del ejército ruso, expulsar a los ocupantes suecos. La intervención rusa fue el primer síntoma de la adquisición de una gran influencia de Rusia en la vida política de la República de las Dos Naciones, lo que con el tiempo se convirtió en una permanente dependencia política ${ }^{8}$.

MAPA 2. Los puertos españoles que participaron en el comercio directo con el Báltico sur, siglo XVIII

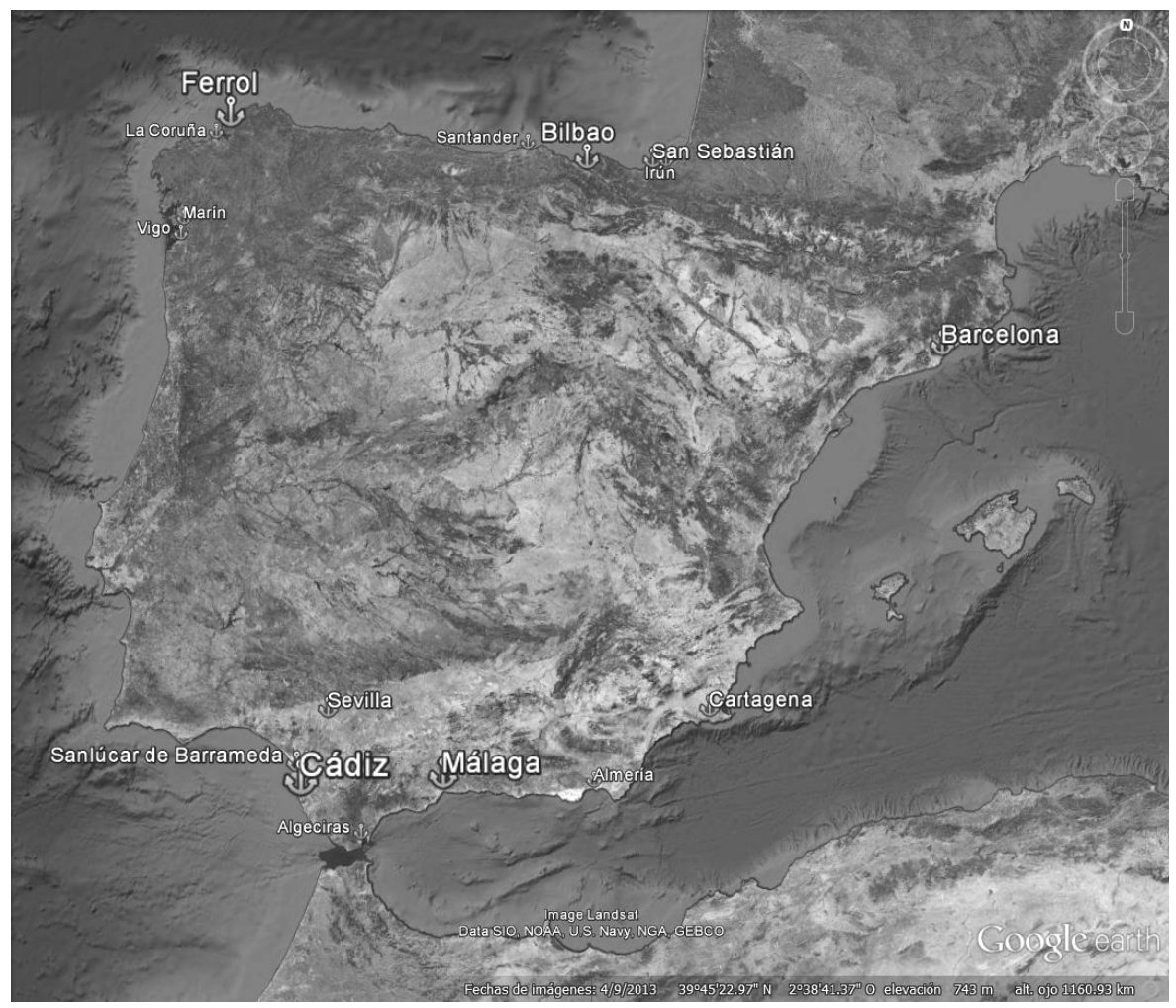

Fuente: propia con base en Google Earth.

Ambas guerras tuvieron su influencia en el comercio entre la región del Báltico sur y España. Al observar el gráfico 1 se percibe que, durante las primeras cuatro décadas del siglo XVIII, el comercio directo prácticamente no existió, situación muy diferente si se compara con la constatada en las últimas

8 JASIENICA, 2007: 68-70. 
décadas del siglo XVII, época en que hubo un movimiento marítimo de un nivel considerable entre la región sur del Báltico y los puertos cantábricos y el gaditano9. Durante esos cuarenta y dos años del siglo XVIII, solo arribaron a los puertos peninsulares veintinueve buques, de los cuales diez transportaron duelas para elaborar barriles, seis cargaron cereales, cuatro barras de hierro y tablones de madera, y siete navegaron con cargamentos mixtos de duelas, astas y tablones, cereales, botellas, cera y lienzo, entre otros géneros. Además, se registraron dos barcos en lastre procedentes de Lübeck con destino a Cádiz $^{10}$. Cabe decir que en ese periodo, de 1700 a 1741, solamente se identificó un registro de transporte de madera para construcción naval; se trata de un barco bajo el mando de Pieter Schoen, originario de Ámsterdam, quien en 1729 realizó la ruta de Stettin a Cádiz ${ }^{11}$.

Es interesante mencionar que durante la Guerra de Sucesión Española los corsarios españoles y franceses capturaron varios barcos provenientes de la región sur del Báltico. Esto fue lo que le ocurrió al buque Król Dawid, de Gdansk, que en 1705 fue capturado y llevado a San Sebastián junto con otros dos barcos propiedad de Daniel Fremanth, comerciante y armador de la misma ciudad polaca, que durante su navegación a Portugal cayeron en manos de corsarios españoles y fueron confiscados por transportar mercancías alemanas. Cabe subrayar que Gdansk en esos tiempos tenía el estatuto de ciudad neutral, sin embargo, durante el conflicto, por ser la ciudad miembro de la Liga Hanseática, fue considerada aliada del Sacro Imperio Romano Germánico, que estaba en guerra contra Francia y España ${ }^{12}$.

Al profundizar sobre la visión geopolítica durante los tiempos de la Gran Guerra del Norte, no podemos olvidar que la Pomerania sueca, la cual tuvo bajo su jurisdicción los puertos de Stralsund, Greifswald, Wolgast, Swinemünde, Stettin y Wismar, fue campo de intensos combates, entre los cuales el crucial

9 Véanse los registros digitales de Sund en http://www.soundtoll.nl/index.php/en/welkom.

10 Registros digitales de Sund. Microfilms núm.: 165, 172, 174, 176, 177, 178, 187, 190, 191, 192, 193, 195, 201, 203, 204, 205, 206, 207, 209, 210. Para simplificar el estudio, en el texto se utilizan las categorías generales como:

Madera para la construcción naval. Se incluyen los registros que mencionan bienes como: troncos, mástiles, vigas, tablones y tablas para el casco y la cubierta, curvatones y estacas.

Cereales y legumbres. Se incluyen los registros que mencionan productos de tierra como: centeno, trigo y cebada, además de legumbres (guisante y frijol blanco) y frutas secas.

Madera para barriles. Se incluyen los registros que mencionan duelas para elaborar barriles.

Madera mixta. Se incluyen todo tipo de maderas, de las cuales no se pudo definir su fin (tablones, duelas, platos y cubiertos de madera).

Cargamento mixto. Se incluyen todos los géneros ya mencionados, más otros como: hierro, brandy, telas, lino, cera, vidrio, cueros, entre otros bienes.

11 Registros digitales de Sund. Microfilm núm. 193/imagen 0407/núm. de registro 418 (en adelante se seguirá el mismo orden).

12 TRZOSKA, 1989: 172-173. 
(durante esta etapa de la guerra, 1710-1716) fue la batalla de Gadebusch (diciembre de 1712), la última gran victoria de Carlos XII. En este enfrentamiento, las tropas suecas bajo el mando del general Magnus Gustafsson Stenbock derrotaron a las fuerzas aliadas de Dinamarca y Sajonia. Asimismo, en dicho periodo se organizaron los asedios de las ciudades-fortaleza de Stralsund (1711-1715), Stettin (1713) y Wismar (1715-1716). Además de los sitios terrestres, estos puertos también sufrieron bloqueos navales y sus embarcaciones en varias ocasiones fueron tomadas por las fuerzas armadas y corsarias de Dinamarca y Rusia ${ }^{13}$.

Al hablar de la guerra de corso, es interesante mencionar que, entre 1711 y 1720 , en la rada de Gdansk se instaló una escuadra rusa compuesta de entre dos y cinco buques de guerra, comandada por Franz Vilbois, para obstaculizar el lucrativo comercio de esta ciudad con Suecia. Por otro lado, el comandante ruso obligó a que las autoridades del puerto establecieran una flotilla corsaria compuesta de cuatro barcos. Los suecos respondieron a estas represalias con ataques de sus corsarios a los barcos con bandera gdanskiana ${ }^{14}$.

GRÁFICO 1. Total de buques del comercio directo entre el Báltico sur y España $(1700-1783)$

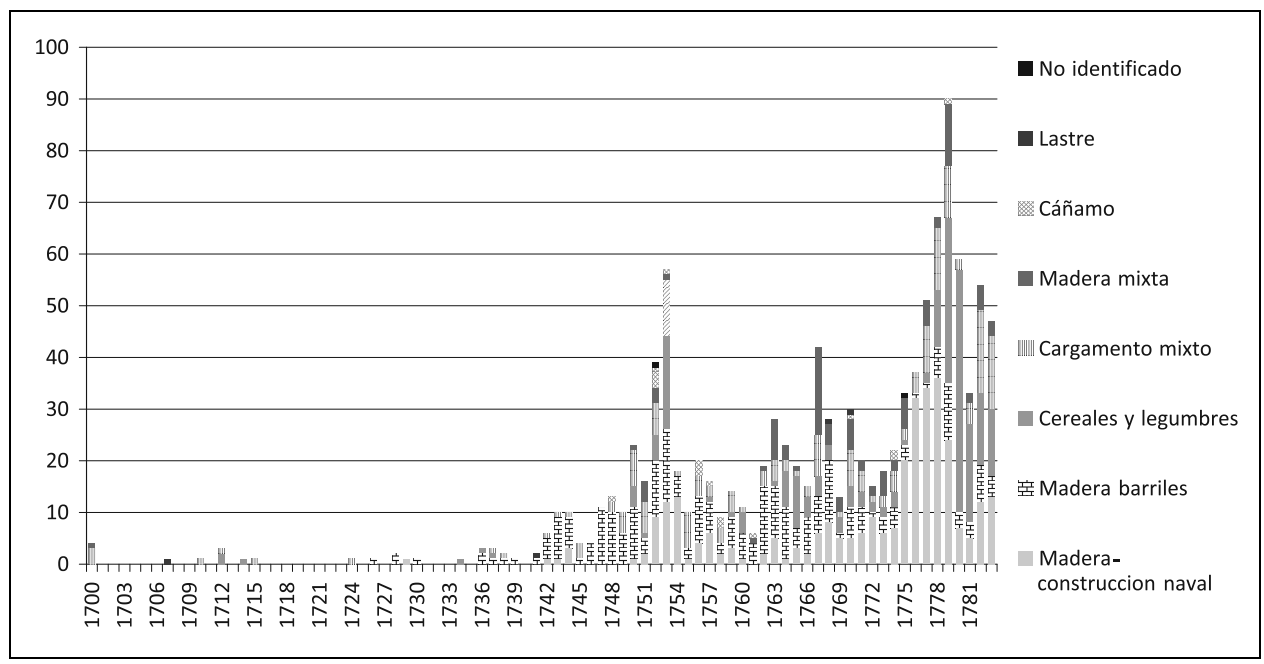

Fuente: registros digitales de Sund, http://www.soundtoll.nl/index.php/en/welkom. Números de microfilms consultados: 165, 172, 174, 176, 177, 178, 187, 190, 191, 192, 193, 195, 201, 203, 204, $205,206,207,209,210,211,212,213,214,215,216,217,218,219,220,221,222,223,224,225$, $226,227,228,229,230,231,232,233,234,235,236,237,238,239,240,241,242,243,244,245$, 246, 247, 248, 249, 250, 251, 252, 253, 254, 255, 256, 257, 258.

13 FROST, 2000: 374-376, 382, 385.

14 TRZOSKA, 46 (Gdansk, 1986): 21. 
Asimismo, entre los años 1701 y 1721, el almirantazgo de República holandesa en varias ocasiones envió escuadras navales a Sund para proteger a sus barcos mercantes y evitar que fueran capturados por los daneses ${ }^{15}$. Probablemente estos asaltos y bloqueos de navegación por el estrecho también afectaron al comercio de los puertos suecos, prusianos y polacos del Báltico sur.

Es notable que tanto la Guerra de Sucesión Española, como la Gran Guerra del Norte, tuvieran un impacto negativo en el comercio directo entre el Báltico sur y España, que en los últimos años del siglo XVII mostraba tendencias de crecimiento. Otro factor que en estas primeras décadas del siglo XVIII tuvo cierta influencia en la reducción de este comercio fue la devolución de Flandes a los Habsburgo (1713) por parte de la Corona española; así, España perdió una región estratégica para el comercio báltico, donde los barcos provenientes de esta área hacían escala antes de seguir su travesía rumbo a la Península Ibérica y el Atlántico ${ }^{16}$. Pero, al analizar la escasez del comercio directo entre el Báltico sur y España durante ese periodo, ha de tomarse en cuenta otro factor: el monopolio de los holandeses e ingleses quienes, al superar militar y económicamente a la Liga Hanseática, tomaron el control sobre el flete y el comercio con los países de la cuenca báltica, por lo que pasaron a convertirse en poderosos proveedores de bienes de importación y exportación de y a Europa Occidental.

Para concluir esta breve descripción histórica de este periodo entre $1700 \mathrm{y}$ 1741, cabe decir que los continuos desacuerdos entre diferentes facciones políticas de la Mancomunidad de Polonia y Lituania en la primera mitad del siglo XVIII culminaron con el estallido de la Guerra de Sucesión Polaca (1733-1735) ${ }^{17}$, acontecimiento que demostró la creciente importancia del estado prusiano, que a partir de ese momento comenzó una agresiva guerra económica contra la República de las Dos Naciones en la que su objetivo primordial consistía en impedir el comercio marítimo de Gdansk, ciudad polaca que, a través del río Vístula, funcionaba como enclave de comunicación con el resto del país ${ }^{18}$.

\section{CAMBIOS GEOPOLÍTICOS Y COMERCIO DIRECTO ENTRE EL BÁLTICO SUR Y ESPAÑA, 1742-1783}

La dinámica del comercio directo entre el Báltico sur y España cambió a partir de 1742, año a partir del cual comenzó a crecer de manera continua el

\footnotetext{
15 CRESPO SOLANA, 8 (Murcia, 2007): 57.

16 CRESPO SOLANA, 8 (Murcia, 2007): 65.

17 CIESIELSKI, 25/2 (Torun, 2013): 81-117.

18 DROZDOWSKI, 1976: 667-676.
} 
número de los barcos que navegaban por la ruta entre ambas regiones. Esta dinámica se mantuvo hasta la Guerra de los Siete Años (1756-1763), cuando la Corona hispana se involucró, a partir de 1761, debido a los acuerdos del III Pacto Familiar con los Borbones franceses. Durante el periodo comprendido entre 1742 y 1761 se registraron en los libros del estrecho de Sund 307 embarcaciones. La mayor intensificación del movimiento marítimo se registró en el año 1753, cuando 57 buques destinados a España pagaron derecho de tránsito (peaje) a la Corona danesa ${ }^{19}$.

Con el fin de aclarar el contexto, conviene presentar una breve historia de Sund. El estrecho de Oresund, o simplemente Sund, separa la isla danesa Selandia (Sjcelland) de Escania (Skåne, actual Suecia). En 1429, Érico de Pomerania (1412-1442), rey de Noruega y Dinamarca, introdujo el cobro de un peaje por el uso de ese paso. Por ello, todos los barcos que cruzaban el estrecho debían detenerse en el embarcadero de Elsinor y pagar el derecho de tránsito a la Corona danesa, independientemente de si el cargamento era de origen danés o se destinaba a dicho reino. El control político de Oresund fue un asunto importante en las historias danesa y sueca porque en varias ocasiones causó fricciones político-militares entre ambas coronas. Dinamarca mantenía su poder en Sund a través de dos fuertes: Kronborg, en Elsinor, y Kärnan, en Helsingborg ${ }^{20}$. El estrecho tiene tan sólo cuatro kilómetros de ancho en el lugar donde están ubicadas ambas fortificaciones y, si un barco se rehusaba a pagar el derecho, podía ser fácilmente cañoneado y hundido. Cabe decir que el peaje también se cobraba en otros dos estrechos daneses: el Gran Belt y el Pequeño Belt. El impuesto del estrecho fue durante cuatro siglos la fuente más importante de ingresos para la Corona danesa. Finalmente, en la Convención de Copenhague de 1857 se abolió este impuesto y los estrechos daneses se convirtieron en aguas internacionales de paso libre para todo tipo de embarcaciones $^{21}$.

Retornando al comercio directo en la región de estudio, es interesante notar que en 1753 y 1754 se enviaron del Báltico sur a España veinticinco buques (doce en el primer año y trece en el segundo) ${ }^{22}$ con cargamentos de madera y pertrechos navales, lo que puede sugerir que la Corona hispana, al observar la creciente tensión política entre Francia y Gran Bretaña, se estaba preparando para fortalecer sus fuerzas navales en el caso de que estallara un conflicto armado que involucrara al país en acciones bélicas al lado de su aliado francés. Probablemente esta acción preventiva, que consistía en sumi-

19 Registros digitales de Sund. Microfilms núm.: 225 y 226.

20 A raíz del tratado de Roskilde (1658), que dio por terminada la guerra entre Dinamarca y Suecia, el primer reino cedió Helsingborg a la Corona sueca. STILES, 1992: 102.

21 MACZAK, 1972: 19-20.

22 Registros digitales de Sund. Microfilms núm. 225, 226 y 227. 
nistrar a la armada real materias primas para la construcción naval, se debió a la política del marqués de la Ensenada, quien desde el año 1750 intentó fundar una flota en La Habana con el objeto de desalojar a los británicos de Walis y de la Costa de los Mosquitos. No obstante, sus planes se vieron arruinados por una conspiración que logró destituirle de su puesto en julio de $1754^{23}$.

GRÁfICO 2. Total de buques de comercio directo entre el Báltico sur y España $(1742-1783)$

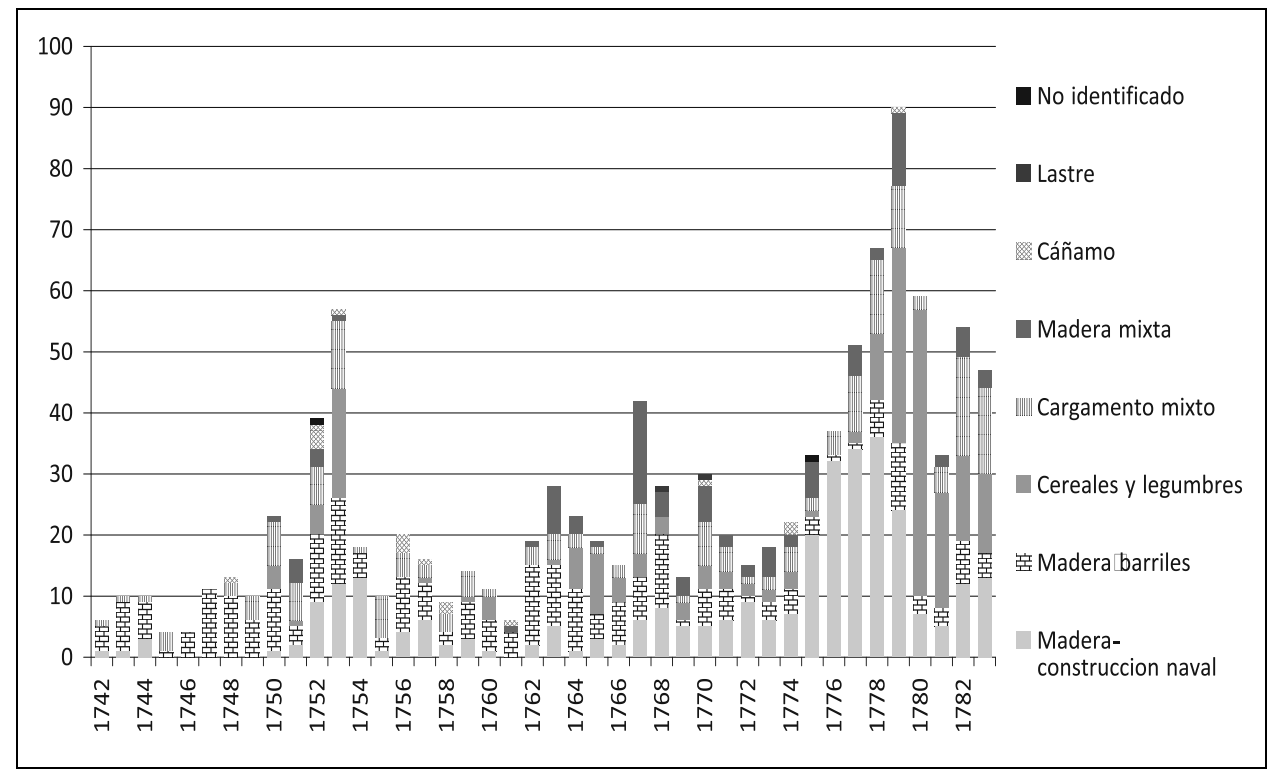

Fuente: registros digitales de Sund, http://www.soundtoll.nl/index.php/en/welkom. Números de microfilms consultados: 211, 212, 213, 214, 215, 216, 217, 218, 219, 220, 221, 222, 223, 224, 225, $226,227,228,229,230,231,232,233,234,235,236,237,238,239,240,241,242,243,244,245$, 246, 247, 248, 249, 250, 251, 252, 253, 254, 255, 256, 257, 258.

Con el estallido del conflicto en 1761, en ese año solo se registraron seis barcos procedentes del Báltico sur con destino a los puertos españoles ${ }^{24}$, caída que se debió a la incorporación de la Corona hispana a la Guerra de los Siete Años. Sin embargo, entre 1762 y 1783 el movimiento marítimo entre ambas regiones volvió a la normalidad y casi se triplicó en comparación con la etapa

23 GÓMEZ URDÁÑEZ, 2001: 57-58.

24 Este número de buques registrados fue más bajo en el periodo comprendido entre 1742 y 1783 . 
anterior (1742-1761). En este periodo se registraron 763 barcos del Báltico sur con destino a España. La mayor intensidad de comercio directo tuvo lugar entre 1775 y 1783, años en los cuales se registraron 471 buques $^{25}$. Esta demanda elevada de bienes se debió a las reformas que Carlos III (1759-1788) puso en práctica después de las crisis administrativa, económica, social y militar, que surgieron en el Imperio después de la vergonzosa derrota de España en la Guerra de los Siete Años ${ }^{26}$.

Por otro lado, la disminución de la influencia político-militar de Holanda y Gran Bretaña en la cuenca báltica abrió el paso para la creación de nuevas potencias regionales (Prusia y Rusia), las cuales año tras año fortalecían su presencia y su posición en la geopolítica y la economía de la región. Este fue el caso de los puertos prusianos (Stettin, Königsberg, Memel y Pillau), que a partir de la década comprendida entre los años 1760 y 1769 comenzaron fuertemente a competir con los puertos suecos y polacos. Además, Königsberg, Memel y Pillau, puertos ubicados en la antigua Prusia Oriental, se convirtieron en importantes centros del comercio ultramarino, especializándose en el tráfico de productos forestales y agrícolas. También, la situación geopolítica de la propia región del Báltico sur permitió el crecimiento y la conformación de las nuevas potencias. Un ejemplo de ello fue la elección del nuevo rey de la Mancomunidad de Polonia y Lituania en el año 1764, cuando la familia de los Czartoryski, con el acuerdo de Prusia, pero sobre todo con el apoyo militar de Rusia, organizó un golpe de Estado contra los partidos patrióticos y reformistas polacos. Esta intervención de las fuerzas armadas rusas sembró la desestabilidad política en el país, que desde 1768 quedó bajo el protectorado de la Rusia de Catalina II, la Grande (1762-1796). Dicho acontecimiento provocó cuatro años más tarde el Primer Reparto del territorio de la Mancomunidad, situación que, por un lado, debilitó la política interna y externa de la República de las Dos Naciones, pero por otro permitió una recuperación de la economía, sobre todo de los grandes magnates y nobles, que en ocasiones colaboraban con Rusia y Prusia a cambio de favores monetarios y cesiones territoriales ${ }^{27}$.

25 Registros digitales de Sund. Microfilms núm.: 234, 235, 236, 237, 238, 239, 240, 241, $242,243,244,245,246,247,248,249,250,251,252,253,254,255,256,257$ y 258 . Es interesante que el mayor número de barcos registrado en ese periodo se produjera en el año 1779 . De las noventa unidades registradas, treinta y dos iban cargadas con cereales y veinticuatro con madera para la construcción naval. Teniendo como base estos datos, con certeza se puede decir que España estaba segura de que participaría en la Guerra de Independencia de Estados Unidos (1776-1783).

26 STEIN, 2005: 61.

27 KONOPCZYNSKI, 2010: 31-34. 


\section{El ANÁliSiS DEL COMERCIO DIRECTO ENTRE EL BÁltico SUR Y ESPAÑa (1700-1783)}

En el periodo que abarca la presente investigación (1700-1783) se registraron en el estrecho de Sund 1099 barcos provenientes del Báltico sur con dirección a España. Se ha mencionado que el mayor volumen de este comercio directo se produjo entre 1742 y 1783, cuando 1070 buques con destino a los puertos hispanos pagaron derecho de peaje. Al analizar los lugares de destino de los cargamentos bálticos, se observa que más de las tres cuartas partes de los barcos registrados $(76,17 \%$ del total) se dirigió a Cádiz (43,68\%), Málaga $(17,29 \%)$ y Ferrol $(15,20 \%)$; sin embargo, otras ciudades portuarias, tanto del Mediterráneo como del Atlántico y del Cantábrico, también participaron en el comercio directo con el Báltico sur (véase Cuadro 1).

CuAdro 1. Puertos españoles que participaron en el comercio directo con el Báltico sur y volumen de barcos registrados en los libros del estrecho de Sund, 1700-1783.

\begin{tabular}{|c|c|c|c|c|c|c|c|c|}
\hline Cádiz & Málaga & Ferrol & Barcelona & Bilbao & $\begin{array}{c}\text { San } \\
\text { Sebastián }\end{array}$ & Sevilla & $\begin{array}{l}\text { Sanlúcar de } \\
\text { Barrameda }\end{array}$ & Cartagena \\
\hline 480 & 190 & 167 & 79 & 50 & 32 & 30 & 18 & 18 \\
\hline $\begin{array}{c}\text { España } \\
\text { (sin espe- } \\
\text { cificación) }\end{array}$ & Santander & $\begin{array}{c}\text { La } \\
\text { Coruña }\end{array}$ & Irún & Vigo & Marín & Algeciras & Almería & \\
\hline 8 & 7 & 7 & 5 & 3 & 2 & 2 & 1 & \\
\hline
\end{tabular}

Fuente: ver Gráfico 1

Los puertos bálticos del litoral meridional que participaron de forma más activa en el comercio directo con España fueron Gdansk (50,14\% del total), Stettin (18,20\%), Memel (10,28\%), Königsberg (8,55\%) y otros (ver Cuadro 2 ).

En este punto es importante mencionar que estas cuatro ciudades se encuentran en las desembocaduras de los ríos Óder, Vístula, Pregolya y Niemen, que conectaban dichos puertos con su Hinterland ${ }^{28}$. Así, mediante la

28 El concepto de Hinterland proviene de la misma palabra alemana que literalmente significa «tierra posterior». El término se utiliza para describir una región o regiones, ubicada(s) detrás de un puerto. Dicha región al mismo tiempo se convierte en abastecedora de mercancías para la exportación, así como en receptora de bienes provenientes de la importación. PACHECO DÍAZ, 2012: 35-36. 
navegación fluvial operada por gabarras, barcazas y balsas ${ }^{29}$, a esos centros de acopio llegaban los productos y bienes regionales para su exportación hacia diferentes destinos de Escandinavia y Europa Occidental. Por otro lado, de estas ciudades portuarias se obtenían las mercancías de importación, que se transportaban por los ríos al interior de la Pomerania Sueca, Prusia Occidental y Oriental, Sajonia, la Mancomunidad de Polonia y Lituania, y Rusia ${ }^{30}$. Se puede decir que el sistema de comunicación fluvial en la región sur del Báltico fue esencial para las economías locales, nacionales e internacionales, ya que desde el siglo XIV hasta el XIX los grandes ríos de la zona funcionaban como autopistas por las cuales se transportaba gran volumen de mercancías con fines comerciales $^{31}$.

CUADRO 2. Puertos del Báltico sur que participaron en el comercio directo con España y volumen de barcos registrados en los libros del estrecho de Sund, $1700-1783$

\begin{tabular}{|c|c|c|c|c|c|c|c|}
\hline $\begin{array}{c}\text { Gdansk/ } \\
\text { Danzig }\end{array}$ & $\begin{array}{l}\text { Szczecin/ } \\
\text { Stettin }\end{array}$ & $\begin{array}{c}\text { Kláipeda } \\
\text { /Memel }\end{array}$ & $\begin{array}{c}\text { Kaliningrado/ } \\
\text { Königsberg }\end{array}$ & Wismar & $\begin{array}{c}\text { Baltisk/ } \\
\text { Pillau }\end{array}$ & Wolgast & $\begin{array}{l}\text { Swinoujscie/ } \\
\text { Swinemünde }\end{array}$ \\
\hline 551 & 200 & 113 & 94 & 65 & 21 & 11 & 9 \\
\hline Lübeck & Rostock & Stralsund & $\begin{array}{c}\text { Kolobrzeg/ } \\
\text { Kolberg }\end{array}$ & Greifswald & $\begin{array}{c}\text { Darlowo/ } \\
\text { Rügenwalde }\end{array}$ & Slupsk/Stolp & \\
\hline 11 & 7 & 5 & 4 & 3 & 3 & 2 & \\
\hline
\end{tabular}

Fuente: ver Gráfico 1.

Es interesante mencionar que algunos de estos puertos de la región se especializaron en un solo tipo de comercio, como sucedió en el caso de Wismar, Stralsund y Greifswald, ciudades que a lo largo de los 84 años que abarca la presente investigación exportaron a España únicamente trigo, centeno y cebadas de diferentes tipos ${ }^{32}$. Estos cargamentos en su mayoría se dirigían a Cádiz, Málaga y Barcelona. La participación de otros puertos españoles en el comercio de cereales y grano provenientes de Wismar, Stralsund y Greifs-

29 En la nomenclatura polaca este tipo de embarcaciones se dividía en dos categorías: 1) de poco calado y con vela (szkuta y dubas); 2) de construcción plana y sin vela (galar y komiega). Además, en el caso del transporte de troncos de madera, se los unía en balsas provisionales (tratwa). FURMAGA y WOJCICKI, 1993.

30 KAZUSEK, 2013: 10-13.

31 TRZOSKA, 1989: 163-164.

32 Registros digitales de Sund. Microfilms núm. 225, 227, 251, 252, 253, 254, 255, 256 y 257. 
wald es prácticamente nula ${ }^{33}$. Esta especialización por un lado se debió a la producción agrícola de su Hinterland y, por otro lado, a los escasos bosques de las aéreas circundantes.

GRÁFICO 3. Participación porcentual de los puertos españoles en el comercio directo con la región sur del Báltico, 1700-1783.

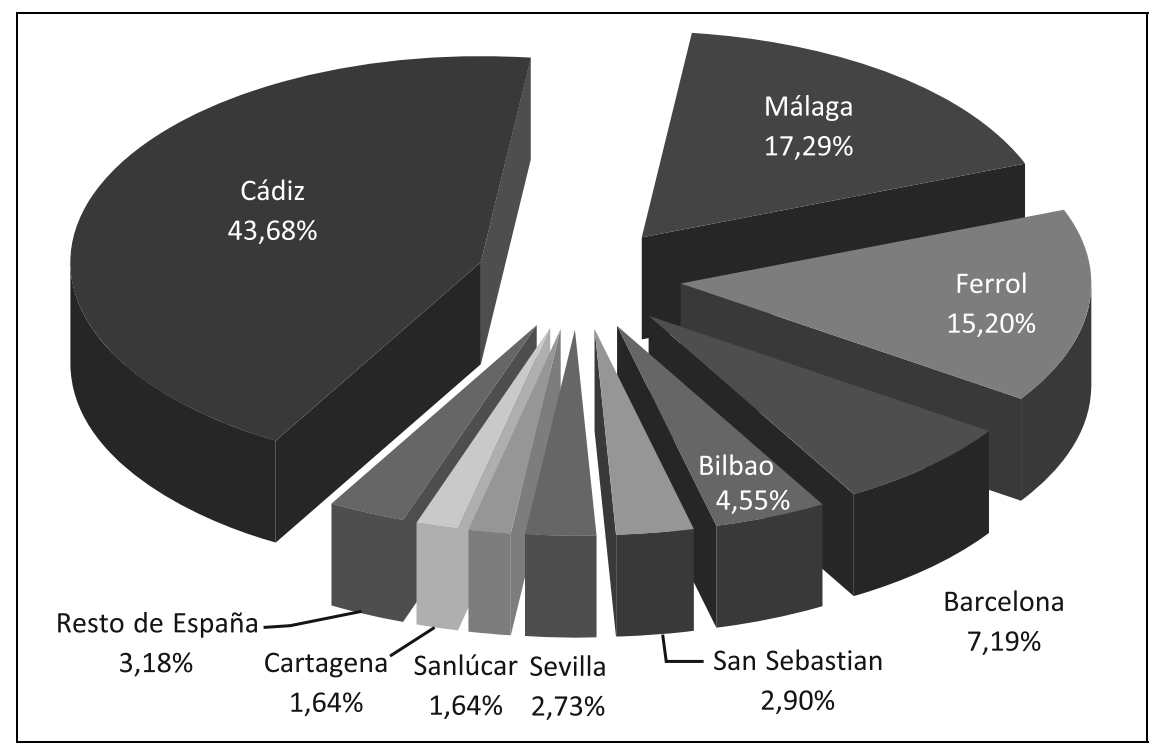

Fuente: ver Gráfico. 1.

En las líneas anteriores ya se han mencionado algunos tipos de cargamentos provenientes del Báltico sur, por lo que se pasará a realizar una presentación de los principales bienes, mercancías y materias primas que se exportaban de los puertos de la Pomerania Sueca, Prusia Occidental y Oriental, y Polonia. Al observar los datos del Cuadro 3, se deduce que tres quintos de los cargamentos estaban compuestos por madera labrada y no labrada (666 barcos). De estos, casi la mitad (308 registros) se envió con el fin de suministrar los bienes forestales necesarios para la construcción naval (vigas, troncos, curvatones, tablones, tablas, palos, mástiles y clavos de madera) a los astilleros españoles. Otro ramo lo componen los registros de la madera transportada para elaborar barriles, es decir, duelas de todo tipo y tamaño, que se registraron en 258 barcos.

33 Solo se registró un envío a otro destino. Se trata de un transporte de 50 loest (1 loest = aproximadamente 2000 kilos) de Wismar a Sevilla en el año 1779. Registros digitales de Sund. Microfilm núm.: 253/0010/1366. 
GRÁfICO 4. Participación porcentual de los puertos del Báltico sur en el comercio directo con España, 1700-1783.

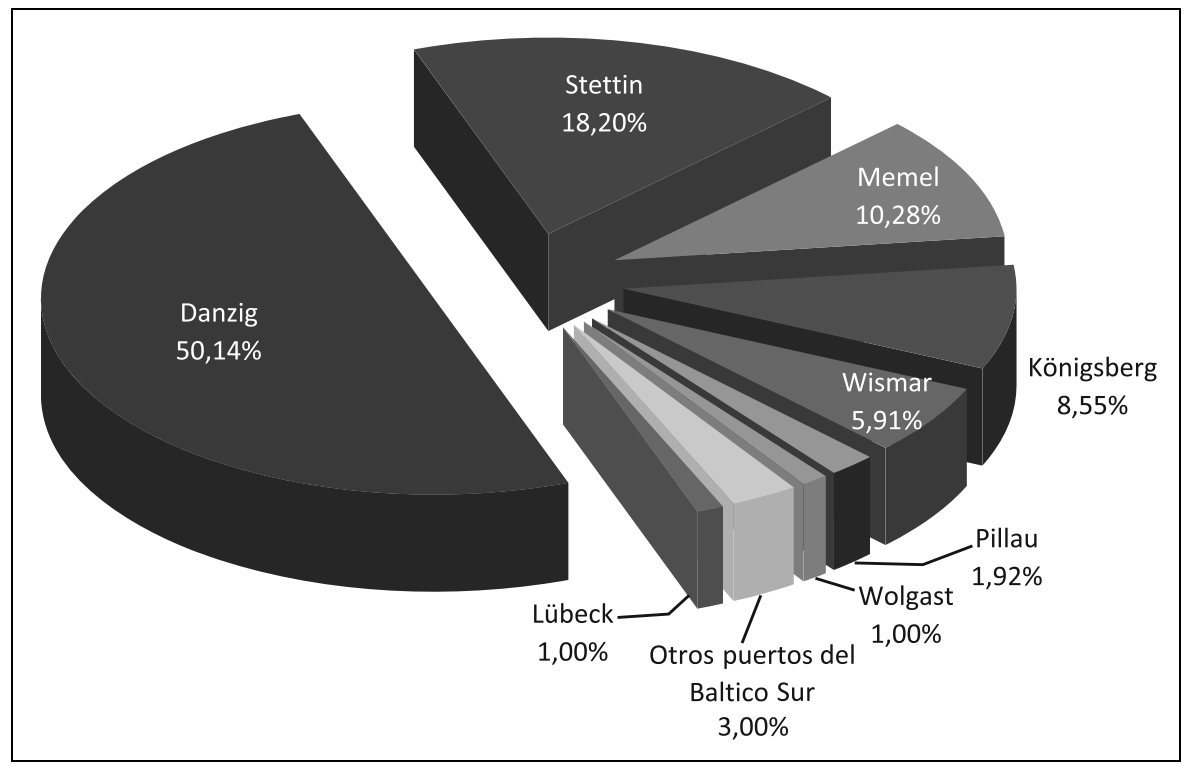

Fuentes: ver Gráfico 1.

Finalmente, cabe mencionar que en los libros de Sund se encontraron otros cien buques que traían cargamentos mixtos, con mezcla de todo tipo de madera labrada (vigas, tablas, tablones, duelas, recubrimientos, acabados, platos, clavos y otros artículos de madera) y no labrada (troncos) con el fin de emplearla en la carpintería general y especializada. Estos barcos cargados de madera para diferentes fines representan casi el $61 \%$ de todos los registros durante el periodo de 1700 a 1783, lo que demuestra que, a causa de la deforestación de los bosques de España que comenzó a finales del siglo XVI, se hizo necesaria la búsqueda de recursos forestales en otras regiones de Europa, entre las que el Báltico manifestó su importancia. Esta demanda se fortaleció como consecuencia de la Ordenanza de Montes de 1748, mediante la cual se pretendía fomentar plantaciones de árboles para la Armada española. Sin embargo, las restricciones del reglamento provocaron el efecto contrario porque los plantadores y pueblos se enfrentaron contra el Estado, conflicto que provocó la disminución drástica de aportaciones madereras para la marina y que obligó a la Corona a buscar este recurso en el Mediterráneo y el Báltico ${ }^{34}$.

34 TORRES SÁNCHEZ, 35 (Salamanca, 2013): 193. 
CuAdro 3. Cargamentos especificados y la cantidad de barcos procedentes del Báltico sur que se registraron en los libros de Sund con destino a España, 1700-1783.

\begin{tabular}{|c|c|c|c|c|c|c|c|}
\hline $\begin{array}{c}\text { Madera para la } \\
\text { construcción } \\
\text { naval }\end{array}$ & $\begin{array}{c}\text { Duelas para } \\
\text { elaborar barriles }\end{array}$ & $\begin{array}{c}\text { Cereales y } \\
\text { legumbres }\end{array}$ & $\begin{array}{c}\text { Cargamento } \\
\text { mixto }\end{array}$ & $\begin{array}{c}\text { Madera } \\
\text { mixta }\end{array}$ & Cáñamo & $\begin{array}{c}\text { Barcos en } \\
\text { lastre }\end{array}$ & $\begin{array}{c}\text { Cargamento no } \\
\text { identificado }\end{array}$ \\
\hline 308 & 258 & 225 & 185 & 100 & 17 & 4 & 2 \\
\hline
\end{tabular}

Fuentes: Ver Gráfico 1.

Los frutos de tierra, como cereales y legumbres, también tuvieron una significativa demanda en el mercado español ya que en casi un cuarto de los registros de Sund figuran estos productos agrícolas. La mayoría de los cargamentos registrados con este tipo de productos eran de trigo y, en menor volumen, de centeno, cebada, guisantes y frijol blanco. Bajo la categoría «cargamento mixto» se agruparon los productos arriba mencionados más otros bienes, entre los que sobresalía la presencia de hierro, cera, lino, lonas, lienzos, textiles, alquitrán, potasa, cuerdas y sogas. Ocasionalmente, en los registros de peaje también aparecen: estopas, telas de seda, bayetas, pólvora, talco, almidón, jabón, pieles de conejo y castor, azulejos, miel, brandy, cerveza, vidrio, botellas y mercancías denominadas «misceláneas». Por último, otras tres categorías que se identificaron a lo largo de la revisión de los registros de Sund fueron: «cáñamo», con diecisiete menciones, «barcos en lastre», con cuatro registros, y finalmente la categoría «cargamento no identificado», de la que solo se registran dos casos. Cabe mencionar que los buques con cáñamo se dirigieron a los puertos de Cádiz (cinco), Ferrol (cuatro), San Sebastián (cuatro), Bilbao (dos) e Irún (dos), y provenían en su mayoría de Königsberg (quince buques), lo que por un lado demuestra la especialidad de cultivo de cáñamo y lino en la Prusia Oriental y, por otra parte, la exclusividad de asiento de este recurso en esta ciudad prusiana ${ }^{35}$.

Es muy probable que algunos bienes incluidos tanto en la categoría de «cargamento mixto», como en la «madera mixta», fueran empleados en la construcción naval española, sobre todo los que llegaron a Cádiz, Ferrol y Cartagena. Un ejemplo de ello lo constituyen los casos de registros de lienzos y lonas, que en ocasiones se especificaban como lonas de velamen ${ }^{36}$. Asimismo, se puede suponer que el alquitrán fue principalmente utilizado en la fabricación y el mantenimiento de barcos.

35 Registros digitales de Sund. Microfilms núm.: 219, 224, 226, 228, 229, 230, 233, 242 , 247 y 253.

36 Un ejemplo de esto es el registro del 31 de julio de 1778, en el que figura que un buque que realizó la navegación de Memel a Cádiz, entre otros productos también transportaba madera y lonas para coser velas. Registros digitales de Sund. Microfilm núm.: 251/0375/734. 
GRÁFICO 5. Porcentajes de los cargamentos especificados procedentes del Báltico sur que se registraron en los libros de Sund con destino a España, 1700-1783

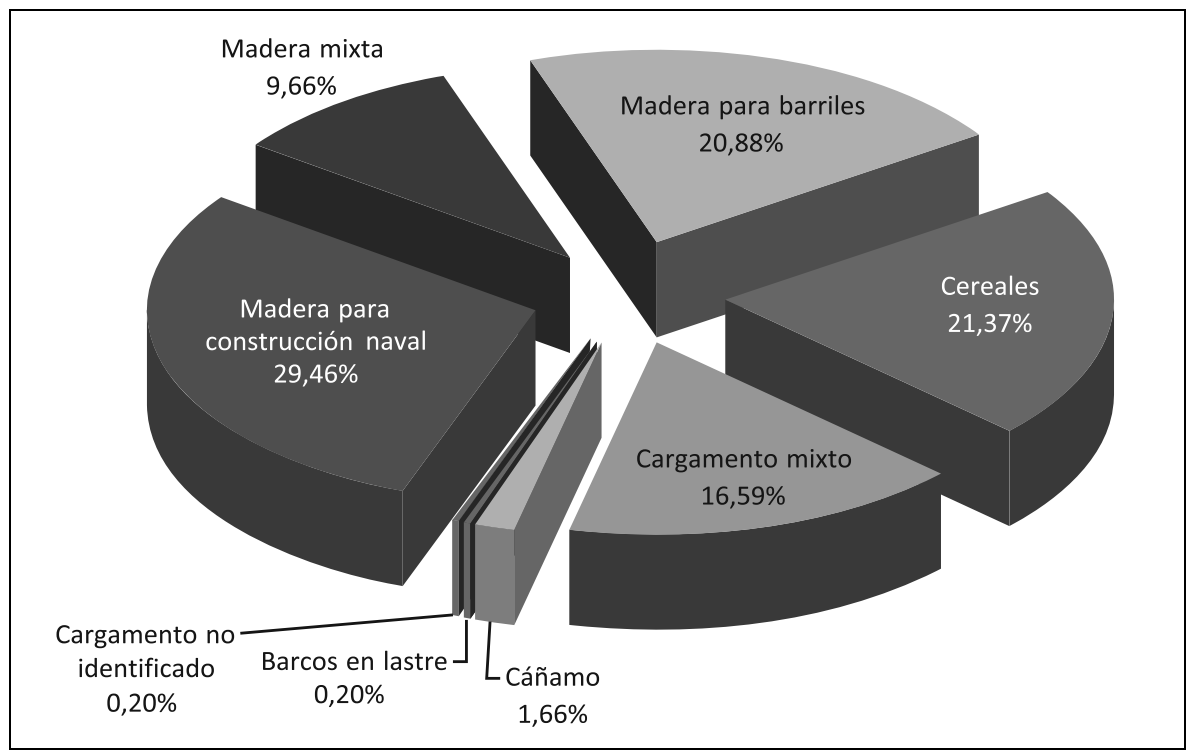

Fuentes: ver Gráfico 1.

Es importante subrayar que, debido a las limitaciones de espacio, en esta publicación solo se estudia con detalle el tema de las maderas para la construcción naval española, dejando para futuros estudios el análisis de otros pertrechos navales provenientes del Báltico sur que se transportaron a los astilleros de España.

Si nos centramos únicamente en los envíos de madera para la construcción naval, resulta que del Báltico sur rumbo a los astilleros españoles partieron 308 barcos, los cuales representaron el $28,03 \%$ del total de los registros de Sund, lo que significa que este producto fue el más demandado en el mercado de suministros. Asimismo, cabe decir que la madera para la industria naval española provenía principalmente de Gdansk con 130 embarcaciones $(42,21 \%)$, de Memel con 91 (29,55\%), de Stettin con 40 (12,99\%) y de Königsberg con $27(8,77 \%)$, y prácticamente se distribuyó entre dos puertos: Cádiz (170 buques) y Ferrol (93). Esta cantidad representó el 85,38\% de todos los envíos madereros con el fin de construir barcos en España. Otras ciudades hispanas que recibieron madera para la construcción naval y figuran en los libros del Sund son: Cartagena (quince), Málaga (once), San Sebastián (nueve), Sevilla (cinco), Bilbao (dos), La Coruña (dos) y Barcelona (uno). 
GRÁfiCo 6. Porcentajes de los cargamentos de madera para la construcción naval española según los puertos del Báltico sur que se registraron en los libros de Sund, 1700-1783

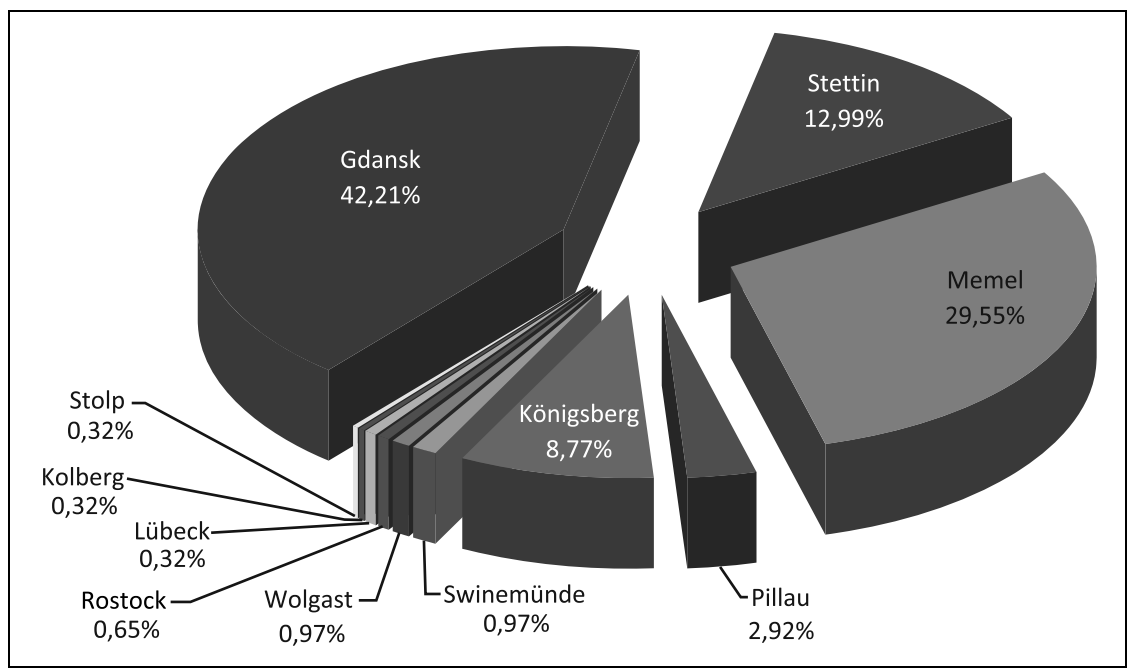

Fuentes: ver Gráfico 1.

GRÁfICO 7. Porcentajes de los cargamentos de madera para la construcción naval española según los puertos receptores en España registrados en los libros de Sund, 1700-1783

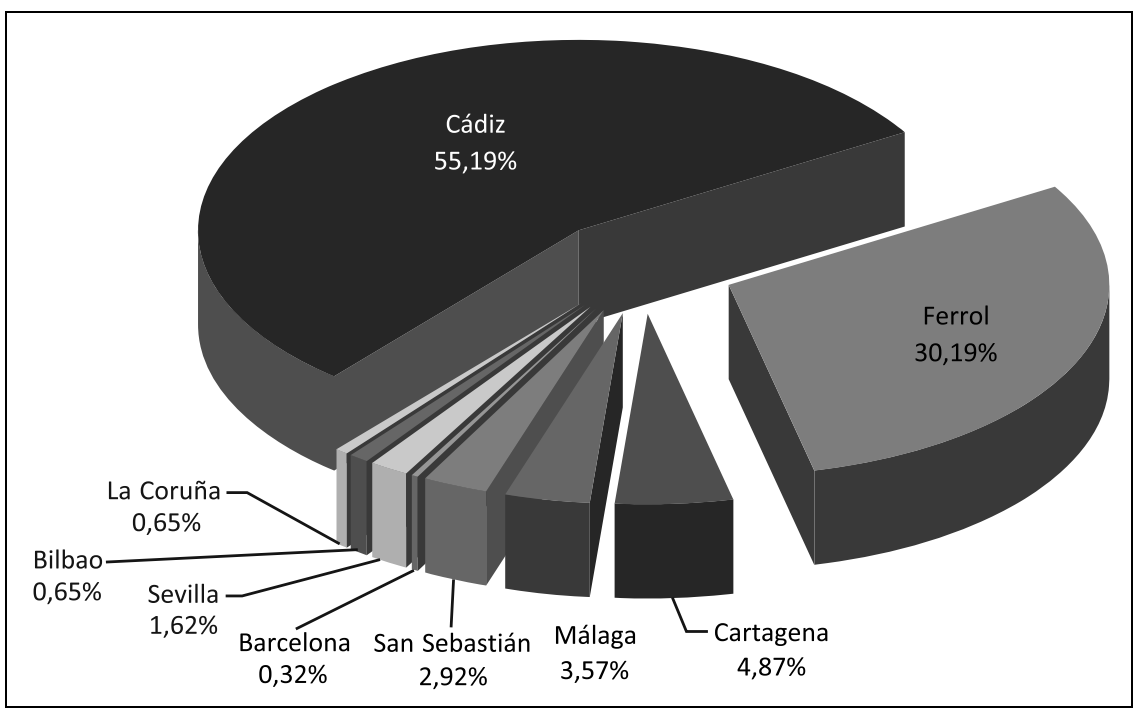

Fuentes: ver Gráfico 1. 
Es importante recordar lo que subraya en sus diversas investigaciones Ana Crespo referente a que Cádiz, por su ubicación estratégica, desempeñaba una función de puerto de escala para los barcos en su navegación hacia el norte de Europa, el Mediterráneo y las Indias. Además, en dicho puerto se descargaban bienes y mercancías extranjeros que después se despachaban a los puertos secundarios alrededor de la Península Ibérica ${ }^{37}$.

\section{El abastecimiento de las MAderas del Báltico SUR PARA la CONS- TRUCCIÓN NAVAL ESPAÑOLA, 1742-1783}

Como se ha mencionado anteriormente que, en el periodo de 1700 a 1741, el comercio directo entre el Báltico sur y España era muy escaso. Cabe subrayar que durante esos cuarenta y dos años solo se registró un cargamento destinado a suministrar madera báltica a la industria naval española. Se trata del transporte de Stettin a Cádiz de 618 vigas y 1320 tablones de cubierta, revisado por los funcionarios daneses el 8 de septiembre de 172938 .

Esta situación cambió a partir de 1742, cuando el comercio directo del Báltico meridional comenzó paulatinamente a ascender. Sin embargo, durante los siguientes diez años la representación de barcos cargados de madera era baja, ya que solo se registraron ocho envíos ${ }^{39}$, de los cuales el más representativo se realizó en el año 1744, cuando de Gdansk partieron hacia Cádiz tres buques cargados con productos forestales. Es interesante que el primer buque, que transportaba vigas de roble, tablones, tableros y duelas para elaborar barriles, se registrara en Sund durante el invierno (el 2 de enero). En cambio, los dos barcos restantes iban en convoy y fueron registrados en los libros del peaje el 15 de julio de 1744. En sus bodegas guardaban troncos, vigas de roble, tablones y tableros de pino, además de duelas para barriles y tazones de ma$\operatorname{dera}^{40}$.

A parte de los cargamentos, es interesante que el primer registro de ese año se realizara en pleno invierno, y llegados a este punto quizás sea conveniente explicar las dificultades que pudieron encontrar los navegantes en el mar Báltico. Más arriba hemos aludido a algunos casos de persecuciones de buques mercantes por parte de las armadas nacionales y de los corsarios, pero

37 CRESPO SOLANA, 8 (Murcia, 2007): 47.

38 Registros digitales de Sund. Microfilm núm.: 193/0407/418.

39 1742: un barco, 1743: un barco, 1744: tres barcos, entre 1745 y 1749: ninguno, 1750: un barco y 1751: dos barcos. Registros digitales de Sund. Microfilms núm.: 211/0462/104, $212 / 0396 / 113,214 / 0335 / 2,214 / 0301 / 64$ у 214/0347/204, 223/0191/384, 223/0368/82 у 223/0372/131.

40 Registros digitales de Sund. Microfilms núm.: 214/0335/2, 214/0301/64 y 214/0347/204. 
un problema todavía más grave lo constituían las condiciones climatológicas que, sobre todo desde el tardío otoño hasta la temprana primavera (noviembre-marzo), dificultaban la navegación por ese mar. Los fenómenos naturales que más afectaban eran las furiosas tempestades, con fuertes vientos, las heladas y el hielo, circunstancias que en múltiples ocasiones paralizaban el movimiento marítimo y la vida portuaria. Por ejemplo, en Gdansk, desde el siglo XIV hasta 1718, la Cámara de Pile o Montón (polaco: Komora Palowa; alemán: Pfahlkammer) suspendía sus labores relacionadas con el registro y la revisión de los cargamentos desde el día de San Martín (11 de noviembre) hasta la primavera, lo que a su vez causaba inconvenientes económicos para los barcos foráneos, que tenían que invernar en el puerto ${ }^{41}$.

Una vez más, retornando al análisis, se observa que en el periodo comprendido entre 1751 y $1774^{42}$ los transportes del Báltico sur tomaron un carácter anual, sin embargo, solamente en dos ocasiones la cantidad de barcos registrados en Sund rebasó las diez unidades al año ${ }^{43}$. Como se ha señalado anteriormente, este incremento entre 1753 y 1754 se debió a las cada vez más fuertes fricciones entre las Coronas borbónicas y Gran Bretaña. Por ello, en 1750, el marqués de la Ensenada inició el proyecto de construir nuevos buques para la Real Armada Española. En consecuencia, dos años más tarde en El Ferrol se puso quilla para construir doce navíos de guerra de porte de setenta cañones ${ }^{44}$, y exactamente a este astillero llegaron trece de los veinticinco buques cargados de madera del Báltico sur. Es importante decir que todos esos barcos salieron de Gdansk, y que su cargamento consistía en vigas, tablones, tablas y tableros. Otros siete barcos con madera registrados en Sund se dirigían a Cádiz y provenían de Gdansk y Stettin. Los cinco restantes arribaron a Bilbao (dos), Málaga (uno), Cartagena (uno) y Barcelona (uno) ${ }^{45}$. Es interesante notar que en el año 1753 se registró un total de 57 embarcaciones rumbo a puertos españoles de los cuales, además de buques madereros, se

41 BIERNAT, 1962: 24.

42 Durante estos veinticuatro años se registraron en el estrecho del Sund, 118 barcos con los cargamentos de maderas provenientes del Báltico sur. Registros digitales de Sund. Microfilms núm.: 224-248.

43 En 1753 se registraron doce barcos y trece en el siguiente año. Registros digitales de Sund. Microfilms núm.: 225, 226 y 227.

${ }^{44} \mathrm{BNE}$, Apéndice al Estado General de la Armada para el año de 1847, signatura: Z/1705/1847, p. 35 .

45 Registros digitales de Sund. Microfilms núm.: 225, 226 y 227. Cabe decir que en esta etapa de la investigación fue difícil identificar los contratistas y asentistas que operaban en el comercio de maderas y bienes forestales para la industria naval española; sin embargo, es seguro que esas licencias se expedían tanto en España, como en la región del Báltico sur. Un buen ejemplo lo constituye el contrato de un armador de Gdansk, Jan Filip Schultz, que a finales de los años cuarenta del siglo XVIII convenció al rey de Polonia, Augusto III, para que se comerciara la madera de los bosques reales con Francia y España. TRZOSKA, 1989: 167. 
enviaron catorce con duelas para elaborar barriles y dieciocho con cereales. Esta intensificación del movimiento marítimo entre el Báltico sur y España probablemente se debió a que la Corona hispana se estaba preparando para el conflicto bélico que finalmente estalló tres años después, y se convirtió en la Guerra de los Siete Años (1756-1763), en la que Francia y España sufrieron vergonzosas derrotas y posteriormente, con la paz de París (1763), tuvieron que reconocer la victoria completa de Gran Bretaña.

Durante los años de la guerra en los cuales participó la Corona hispana (1761-1763), el comercio directo con la región báltica disminuyó. Sin embargo, ya en la segunda mitad del año 1763 comenzó su recuperación, y hasta 1774 los registros de los buques madereros del Báltico sur volvieron al nivel que tenían antes de la guerra. El movimiento más notable se presentó en 1768 y 1772, cuando se registraron respectivamente ocho y nueve barcos cargados de madera para la construcción naval española provenientes de Gdansk (siete), de Königsberg (cuatro), de Memel (tres) y de Stettin (tres), y que se dirigían a Cádiz (doce), a El Ferrol (tres), a Cartagena (uno) y a San Sebastián (uno) ${ }^{46}$.

Desde el año 1775 hasta el involucramiento de España en la Guerra de Independencia de Estados Unidos en 1779, la tendencia a importar maderas del Báltico sur alcanzó una envergadura nunca adquirida después, dado que durante esos cuatro años se registraron en Sund 146 buques madereros destinados a los astilleros españoles, un volumen que representa más de $50 \%$ del total del movimiento marítimo en esos años. ${ }^{47}$ La mayoría de esos barcos provenía de Gdansk (56), de los puertos de Prusia Oriental (68) ${ }^{48}$ y de Stettin (15), lo que demuestra, por un lado, que la ciudad polaca de Gdansk todavía mantenía su posición privilegiada en el comercio directo con España. Sin embargo, a partir del año 1772, cuando se realizó el Primer Reparto del territorio de la Mancomunidad de Polonia y Lituania, comenzó a ceder su posición monopolista debido a la cada vez más agresiva política económica de las autoridades prusianas, quienes pusieron sus aduanas en las entradas al puerto para obstaculizar el contacto de la ciudad con el mundo exterior vía el río Vístula y el Báltico ${ }^{49}$.

En cuanto a la madera proveniente de los bosques circundantes a los ríos Vístula y Niemen que se había almacenado en Gdansk y en los puertos de Prusia Oriental, una gran parte se destinó a Cádiz (71), El Ferrol (58) y Car-

46 Registros digitales de Sund. Microfilms núm.: 240/0434/363, 240/508/476, 240/0603/448, 240/0636/250, 241/0176/98, 241/0245/186, 241/0298/459, 241/0334/193, $245 / 0059 / 11,245 / 0349 / 925,245 / 0419 / 34,245 / 0447 / 380,245 / 0497 / 272,245 / 0510 / 414$, 245/0514/452, 245/0520/513 y 246/0041/592.

47 Entre 1775 y 1779 se registró un total de 278 barcos que realizaron la ruta entre el Báltico sur y España. Registros digitales de Sund. Microfilms núm. 248-253.

48 Memel: 49, Königsberg: 12 y Pillau: 7.

49 BIERNAT, 1962: 22. 
tagena (8). Es interesante el caso del astillero mediterráneo, el cual entre 1775 y 1779 recibió barcos madereros de solo un puerto, el puerto de Memel, lo que sugiere que probablemente se expidió una licencia exclusiva para algún comerciante español o prusiano de aquella ciudad de la Bahía de Curlandia, para que suministrara a Cartagena los bienes forestales necesarios para la construcción de buques ${ }^{50}$. En cambio, los envíos a los astilleros gaditano y ferrolano procedían de toda la región del Báltico sur, con una dominante participación de los puertos de Gdansk y Memel. Este es el caso del año 1778, cuando en los libros de Sund se registraron 36 barcos con madera destinada a la industria naval española (el mayor número de todos los envíos registrados durante el periodo estudiado en este trabajo). Resulta que la mayoría de los buques consignados en ese año procedió de Gdansk (veintiuno) y de Memel (diez), donde tan solo en un mes (entre el 7 de octubre y el 8 de noviembre) se registraron trece buques con carga de mástiles, astas, vigas, vigas de pino, tablones y tablas, de los cuales doce se dirigieron a El Ferrol y uno a Cartagena. Cabe subrayar que once de esos barcos salieron de Gdansk y solo dos de Memel $^{51}$.

En ese periodo comprendido entre 1775 y 1779, en los astilleros de El Ferrol y Cartagena se puso la quilla para construir siete fragatas y cinco navíos de guerra, el más grande de los cuales fue el Purísima Concepción, con 114 cañones ${ }^{52}$. Sin embargo, el aspecto que más llama la atención durante ese tiempo es la falta de participación del astillero de Cádiz en la construcción de buques, lo que hace suponer que probablemente el puerto gaditano se convirtió en el lugar de escala para los buques madereros, y la ciudad en un almacén de las materias forestales, que de allí se distribuían a otras localidades en el Mediterráneo (Cartagena y Málaga), en el Atlántico (El Ferrol) y posiblemente en las Indias (La Habana).

Finalmente, en los últimos años que abarca la presente investigación (1780-1783), el nivel de los envíos de madera para la construcción naval disminuyó significativamente ya que en los libros de Sund solo se registraron 37 buques madereros, los cuales cedieron la prioridad al abasto de alimentos para las tropas y la marina, que desde 1779 participó abiertamente en la Guerra de Independencia de Estados Unidos. Durante los cuatro años del conflicto bélico se registraron en Sund 93 embarcaciones cargadas de productos agrícolas, los cuales se enviaron con el fin de saciar las necesidades alimenta-

50 Registros digitales de Sund. Microfilms núm.: 249/0050/1764, 249/0055/1810, 250/0421/2177, 251/0551/1623, 252/0026/2211, 252/0043/2347, 253/0076/915 у 253/0091/1134.

51 Registros digitales de Sund. Microfilms núm.: 252/0026/2210, 252/0030/2245, 252/0036/2289, 252/0037/2297, 252/0039/2317, 252/0041/2328, 252/0041/2329, 252/0041/2331, 252/0145/749, 252/0146/752, 252/0146/756 у 252/0153/808.

$52 \mathrm{BNE}$, Buques de guerra que ha tenido la Marina Real de España desde principio del siglo 1500, 1830, signatura: Mss. 11307. 
rias del ejército español. La mayoría de esos envíos se destinó tan solo a dos puertos: Cádiz (45 barcos) y Barcelona (39) ${ }^{53}$.

\section{CONCLUSIONES}

El propósito de esta investigación ha sido establecer un primer acercamiento al tema del comercio directo entre España y la región sur del Báltico durante la época de la navegación a vela, una temática escasamente abordada por la historiografía española, en la cual el Báltico se presenta de una manera generalizada y a través de fuentes holandesas e inglesas, sin ubicarlo como un espacio marítimo relevante en las economías de los países occidentales de Europa, e incluso de España. También es probable que dicho mar no haya despertado interés en los estudios históricos españoles debido a su lejanía y quizás, más importante aún, debido a las diferencias lingüísticas.

En este artículo, a través de los registros digitales de Sund, ha sido posible dar un primer paso para profundizar en nuestro conocimiento sobre la historia económica y marítima de España y, además, para reducir el vacío en cuanto al tema del comercio directo de este país con los puertos del Báltico sur. El intercambio que según la historiografía europea surgió en los tiempos del esplendor de la Liga Hanseática (siglos XIV y XV) continúa hasta la fecha. No obstante, por las limitaciones comentadas, en la presente aportación se decidió estudiar solo el periodo entre 1700 y 1783, que abarca diferentes dinámicas económicas y significativos cambios geopolíticos para ambas regiones. Por otro lado, esta limitación nos abre el paso a futuros estudios sobre el comercio tanto a nivel regional, como a nivel global, que se realiza a través del proyecto Contractor State Group, en el cual participan investigadores de varios países europeos y americanos ${ }^{54}$.

Fundándonos en los datos recogidos en los libros de peaje de Sund, ha sido posible contabilizar los barcos con cargamentos específicos, entre los que sobresalieron los que transportaban maderas para la construcción naval, duelas para la elaboración de barriles y los que cargaban cereales y legumbres (791 registros). Estos tres ramos formaron los principales renglones de las importaciones españolas desde la región sur del Báltico, al aportar más de las tres cuartas partes del total de los registros del estrecho (1099). Las ciudades bálticas que tenían mayor participación en este comercio directo fueron Gdansk (Danzig), Szczecin (Stettin), Kláipeda (Memel), Kaliningrado (Königsberg) y Wismar. Los puertos españoles más beneficiados por este comercio fueron Cádiz, Málaga, El Ferrol, Barcelona y Bilbao. Entre ellos, el puerto gaditano

53 Registros digitales de Sund. Microfilms núm. 253-258.

${ }^{54}$ La página web del proyecto es: http://www.unav.edu/centro/contractorstate/ 
tuvo una posición monopolista ya que durante los 84 años que abarca el estudio se dirigieron a esta ciudad 480 barcos (43,68\% del total). Al hablar sobre el monopolio gaditano, no podemos olvidar que en la región del Báltico sur tuvo una posición privilegiada el puerto polaco de Gdansk, que entre $1700 \mathrm{y}$ 1783 despachó 551 barcos a España, lo que representa el 50,14\% de todos los buques registrados en Sund.

Otro fin de este estudio ha sido la presentación del comercio directo de maderas provenientes del Báltico sur para la construcción naval española. Se pudieron contabilizar 308 barcos (28,03\% del total de los registros) con este tipo de cargamento, lo que ubica este producto en primer lugar en cuanto a los bienes de mayor demanda que importaban los comerciantes españoles. La mayor parte de la madera se expidió desde Gdansk, 130 embarcaciones (42,21\% del total de los registros); Memel, 91 (29,55\%); Stettin, 40 (12,99\%) y Königsberg, 27 (8,77\%); y practicamente se distribuyó entre Cádiz y El Ferrol (263 buques, $85.38 \%$ del total de los registros), pero también arribaron transportes menores a Cartagena, Málaga, San Sebastián, Sevilla, Bilbao, La Coruña y Barcelona.

Es importante subrayar que a lo largo de esta investigación se han presentado varios obstáculos que por falta de tiempo y limitación de recursos no se pudieron resolver y que requieren nuevos estudios. Entre ellos destacan las dificultades para contabilizar el volumen de la madera, ya que los registros contienen diferentes parámetros y medidas entre las que destacan: contados por piezas, por carga (danés: laest), por sexagena (danés: skok), por schefell (danés: stein) y por libras navales (danés: skippund). La unificación de estas medidas, así como el nivel de inversiones económicas que asignó la Corona española para suministrar madera del Báltico a sus astilleros, no se pudieron examinar durante esta primera etapa de la investigación, pero su estudio queda pendiente para futuras aportaciones.

En esta misma línea habrá que profundizar en la presencia y la posición de contratistas y asentistas, tanto del Báltico sur como de España, en este comercio directo. Todavía quedan por responder preguntas como: ¿quiénes fueron?, ¿qué estatuto social tuvieron? y ¿cómo llegaron a obtener las licencias para comerciar las maderas?

Desafortunadamente, los registros del Sund no aportan los nombres de los dueños de los cargamentos y de las embarcaciones, datos que nos podrían facilitar la búsqueda de los contratistas en las dos regiones. Tampoco hablan del tipo y calado de los barcos utilizados en este comercio. En compensación, los registros nos aportan información sobre la nacionalidad de la tripulación y los nombres, apellidos y lugares de origen de los capitanes que gobernaban las embarcaciones, quienes en ocasiones eran sus dueños. De este modo, de las cuentas registradas se desprende que en este tráfico dominaron los capitanes holandeses, británicos y escandinavos, mientras que se dejaba tan sólo un quinto de este comercio directo en manos de capitanes originarios de los 
puertos de los que provenía el cargamento, aspecto que también necesitará una profundización futura.

En definitiva, que si bien este comercio directo quizás fuera escaso en su conjunto, no obstante, sirvió para reducir la hegemoneidad angloholandesa en el tráfico con las diferentes regiones del Báltico.

\section{BIBLIOGRAFÍA}

Attman, Artur, The Russian and Polish Markets in International Trade, 1500-1650, Gothenburg, The Institute of Economic History of Gothenburg University, 1973.

Barkham, Michael, «La construcción naval vasca en el siglo XVI: la nao de uso múltiple», Vasconia. Cuadernos de Historia-Geografia, 3, (Donostia, 1984), 103-126.

Biernat, Czeslaw, Statystyka obrotu towarowego Gdanska w latach 1651-1815, Warszawa, PWN, 1962.

Bogucka, Maria, Gdańsk jako ośrodek produkcyjny w XIV-XVII wieku, Warszawa, Wydawnictwo Naukowe PWN, 1962.

Bogucka, Maria, Handel zagraniczny Gdańska w pierwszej połowie XVII wieku, Warszawa-Kraków, Ossolineum-PAN, 1970.

Calvo, José, La guerra de Sucesión, Madrid, Anaya, 1988.

Casado Soto, José Luis, «La construcción naval hispana en época moderna», en Cau Ontiveros, Miguel Ángel y Nieto Prieto, Francisco Xavier (coords.), Arqueología náutica mediterránea, Girona, Centre d'Arqueologia Subacuàtica de Catalunya, 2009; 393-410.

Casado Soto, José Luis, Los barcos españoles del siglo XVI y la Gran Armada de 1588, Madrid, San Martín, 1988.

Cerezo Martínez, Ricardo, «Despliegue de las Escuadras y de la Armada de la Monarquía Hispánica a fines del siglo XVI y principios del siglo XVIII», en Temas de historia militar: $2^{\circ}$ Congreso de Historia Militar, (Zaragoza); 117-142.

Cerezo Martínez, Ricardo, Las Armadas de Felipe II, Madrid, San Martín, 1989.

Ciesielski, Tomasz, "Potencjał militarny Rzeczypospolitej Obojga Narodów w okresie polskiej wojny sukcesyjnej 1733-1735. Wybrane aspekty", Klio. Czasopismo poświęcone dziejom Polski i powszechnym, 25/2, (Torun, 2013); 81-116.

Crespo Solana, Ana, «El comercio holandés y la integración de espacios económicos entre Cádiz y el Báltico en tiempos de guerra (1699-1723)», Investigaciones de Historia Económica, 8, (Murcia, 2007): 45-76.

Crespo Solana, Ana, «La ruta del Levante: Cádiz en el tráfico marítimo neerlandés con sus mercados mediterráneos y orientales en los siglos XVII y XVIII», en Economía Marítima, Cádiz, San Fernando, 1998: 145-154.

Crespo Solana, Ana, El comercio marítimo entre Ámsterdam y Cádiz (1713-1778), Madrid, Banco de España, 2000.

Crespo Solana, Ana, Entre Cádiz y los Países Bajos: una comunidad mercantil en la ciudad de la Ilustración, Cádiz, Fundación Municipal de Cultura, 2001. 
Davis, Ralph, The Rise of the Shipping Industry in the Seventeenth and Eighteenth Centuries, London, Macmillan, 1962.

Díaz Ordóñez, Manuel, «El riesgo de contratar con el enemigo. Suministros ingleses para la Armada española en el siglo XVIII», Revista de Historia Naval, 80, (Madrid, 2003): 65-73.

Díaz Ordóñez, Manuel, «Relaciones laborales en los arsenales de Marina del Dieciocho», en Estudios de Historia Naval: actitudes y medios en la Real Armada del siglo XVIII, Murcia, Universidad de Murcia/Ministerio de Defensa, 2013; 245-290.

Díaz Ordóñez, Manuel, Amarrados al Negocio. Reformismo borbónico y suministro de jarcia para la Armada Real (1675-1751), Madrid, Ministerio de Defensa, 2010.

Drozdowski, Marian, “Zabiegi Prus o ograniczenie suwerennosci Rzeczpospolitej w poczatkach panowania Stanislawa Augusta. Zniesienie cla generalnego", en Biskup, Marian (coord.), Ars histórica. Prace z dziejow powszechnych i Polski, Poznan, UAM, 1976; 667-676.

Fedorowicz, Jan, England's Baltic Trade in the Early Seventeenth Century: a Study in Anglo-Polish Commercial Diplomacy, Cambridge, Cambridge University Press, 1980.

Frost, Robert, The Northern Wars. War, State and Society in Northeastern Europe 1558-1721, Harlow, Longman, 2000.

Furmaga, Leslaw y Wojcicki, Jozef, Mały słownik morski, Gdynia, Mittel, 1993.

Glete, Jan, Navies and Nations: Warships, Navies and State Building in Europe and America, 1500-1860, II vol., Stockholm, Almqvist\&Wiksell International, 1993.

Glete, Jan, War and the State in Early Modern Europe: Spain, the Dutch Republic and Sweden as Fiscal-military States, 1500-1660, London, Routledge, 2002.

Glete, Jan, Warfare at Sea, 1500-1650: Maritime Conflicts and the Transformation of Europe, London, Routledge, 1999.

Gómez Urdáñez, José Luis, «Fernando VI», Los Borbones, vol. III, Madrid, Arlanza Ediciones, 2001.

Goodman, David, Spanish Naval Power, 1589-1665: Reconstruction and Defeat, Cambridge, Cambridge University Press, 1997.

Heeres, Willem y Noordegraaf, Leo, From Dunkirk to Dantzig: Shipping and Trade in the North Sea and the Baltic, 1350-1850, Hilversum, Verloren, 1988.

Horlings, Edwin, The Economic Development of the Dutch Service Sector 18001850: Trade and transport in a pre-modern economy, Amsterdam, NEHA, 1995.

Israel, Jonathan, Dutch Primacy in World Trade, 1585-1740, Oxford, Oxford University Press, 1990.

Janzen, Olaf, Merchant organization and Maritime Trade in the North Atlantic: 1660-1815, Newfoundland, St. John's, 1998.

Jasienica, Pawel, Rzeczpospolita obojga narodów. Dzieje agoni. Warszawa, Pruszynski i S-ka, Tom III, 2007.

Kahk, Juhan y Tarvel, Enn, An Economic History of the Baltic Countries, Stockholm, Almquist\&Wiksell International, 1997. 
Kamen, Henry, Felipe $V$. El rey que reinó dos veces, Madrid, Editorial Temas de Hoy, 2000.

Kazusek, Szymon, Handel zagraniczny Korony w końcu XVIII wieku. Tabele statystyczne, $t$. 1 i 2 Export $i$ Import $w$ latach 1786-1790, Kielce, Uniwersytet Jana Kochanowskiego, 2013.

Konopczynski, Wladyslaw, Pierwszy rozbiór Polski, Kraków, Arcona, 2010.

Maczak, Antoni, Między Gdańskiem a Sundem: studia nad handlem battyckim od połowy XVI do połowy XVII wieku, Warszawa, PWN, 1972.

North, Michael y Minchinton, Walter, History of the Northern Seas. A Select Bibliography, VI vol., Exeter, Exeter University, 1984-88.

North, Michael, From the North Sea to the Baltic: Essays in Commercial, Monetary and Agricultural History, 1500-1800, Aldershot, Ashgate, 1996.

Oakley, Stewart, War and Peace in the Baltic, 1560-1790, London, New York, Routledge, 1993.

Odriozola Oyarbide, Lourdes, Construcción naval en el País Vasco XVI-XIX. Evolución y análisis, San Sebastián, Ángel Apraiz Eusko Ikaskuntza, 1996.

Ormrod, David, The Rise of Commercial Empires. England and the Netherlands in the Age of Mercantilism, 1650-1770, Cambridge, Cambridge University Press, 2003.

Pacheco Díaz, Argelia, Relaciones comerciales entre Hamburgo, Puerto Rico y St. Thomas: 1814-1867, Morelia, IIH-Universidad Michoacana de San Nicolás de Hidalgo, 2012.

Pearson, C.W., England's Timber Trade in the Last of the 17th and First of the 18th Century, More Especially with the Baltic Sea (1869), Whitefish, Kessinger Publishing, 2009.

Pérez Mallaina Bueno, Pablo, Política naval española en el Atlántico 1700-1715, Sevilla, Escuela de Estudios Hispano-Americanos, 1982.

Rahn Phillips, Carla, Seis galeones para el rey de España: la defensa imperial a principios del siglo XVII, Madrid, Alianza, 1991.

Serrano Mangas, Fernando, Función y evolución del galeón para la Carrera de Indias, Madrid, Mapfre, 1992.

Serrano Mangas, Fernando, Galeones de la Carrera de indias. 1650-1700, Sevilla, Escuela de Estudios Hispano-Americanos, 1986.

Staszewski, Jacek, August II Mocny, Wrocław, Ossolineum, 1998.

Stein, Stanley y Barbara, El apogeo del imperio: España y Nueva España en la era de Carlos III, 1759-1789, Barcelona, Crítica, 2005.

Stiles, Andrina, Sweden and the Baltic, 1523-1721, London, Hodder\&Stoughton, 1992.

Torres Sánchez, Rafael, «Administración o asiento. La política estatal de suministros militares en la monarquía española del siglo XVIII», Studia Historica: Historia Moderna, 35, (Salamanca, 2013): 159-199.

Trzoska, Jerzy, "Sprawa kaprów królewskich w Gdansku w polityce Augusta II i Piotra I (1716-1721)”, 46, Rocznik Gdanski, (Gdansk, 1986): 23-48. 
Trzoska, Jerzy, Żegluga, handel i rzemiosło $w$ Gdańsku $w$ drugiej połowie XVII $i$ XVIII wieku, Gdańsk, Uniwersytet Gdański, 1989.

Voltes, Pedro, La guerra de Sucesión, Barcelona, Planeta, 1990.

Zabala Uriarte, Aingeru, «El marco de la construcción naval vizcaína del siglo XVIII al XXI», Itsas Memoria: revista de estudios marítimos del País Vasco, 2, (San Sebastián, 1998): 297-306.

Zabala Uriarte, Aingeru, El comercio y tráfico marítimo del Norte de España en el siglo XVIII, Donostia, Haranburu, 1983.

Recibido: 13/11/2014

Aceptado: 07/04/2015 